\title{
The effect of sound therapy on reading skills of students with reading difficulties.
}

\author{
Zahra Torabi $^{{ }^{*}}$ Mahnaz Estaki $^{2}$ Roya Kochak Entezar ${ }^{3}$ Nastaran Sharifi ${ }^{4}$ \\ ${ }^{1}$ Department of psychology, Tehran Center Branch, Islamic Azad University, Tehran, Iran. \\ ${ }^{2}$ Department of psychology, Tehran Center Branch, Islamic Azad University, Tehran, Iran \\ Email: Mah.estaki@iautcb.ac.ir \\ ${ }^{3}$ Department of psychology, Tehran Center Branch, Islamic Azad University, Tehran, Iran. \\ Email: Roy.Kochak_Entezar@iauctb.ac.ir \\ ${ }^{4}$ Department of psychology, Tehran Center Branch, Islamic Azad University, Tehran, Iran. \\ Email: n.sharifi@ iauctb.ac.ir \\ *Corresponding author. Email: zah.torabi.phy@iauctb.ac.ir
}

\begin{abstract}
The lack of success in acquiring reading skills in early school years can deeply prevent students from achievement in most other educational subjects. Research shows that most of children with reading and learning complications suffer from problems in auditory processing. It may therefore be suitable for those who have reading difficulties be treated with sound therapy. This study aimed to assess the effect of sound therapy on reading skills of students with reading difficulties. This study was a quasi-experimental design with pre-posttest and control group. The sample group was 20 students who were studying in elementary school (third grade). They were selected by available sampling method and assigned randomly to two experimental and control groups. Data were collected by Reading \& Dyslexia Test (Karami nori \& Moradi 1378). After pre-test the experimental group for 20 sessions was trained by sound therapy while the control group received no intervention. Then, all the subjects were tested by post-test. The statistical models were the Analyze of Covariance (ANCOVA). In the post-test, mean of reading skills in experimental group decreased significantly. This difference also was significant for all subscales of reading skills except Rhyme and Reading non-words ( $p=0.07,0.96$ ). The findings show that sound therapy has significant effect on reading skills and in students with reading difficulties.
\end{abstract}

Keywords: sound therapy, reading skills, learning difficulties, students. 


\section{Introduction}

Reading is a kind of mental-lingual process based on the visual information, reader's awareness, as well as phonological and semantic rules. It is the product of cognitive and linguistic capabilities, prior knowledge, and getting specific reading skills (Allah Radi, 2001). This skill is the most fundamental learning tool for students, since reading, and comprehension are the basic requirements to acquire any type of written information(Sen , 2009). Children with poor reading skills can be classified into dyslexic children, and non- dyslexic ones with lower intellectual ability or other problems. Reading difficulties is defined as reading performance or spelling skills lower than the required level based on child's age, intelligence quotient, and training(Palomo-Álvarez $\&$ Puell, 2009). Reading difficulties are important because they can deter educational progression. The lack of success in acquiring reading skills in early school years can deeply prevent children from achievement in most other educational subjects. Anyway, it seems that most researches are devoted to the problems of students suffering from dyslexia, and children with poor reading skills but without dyslexia are to some extent ignored.

One of the basic prerequisites of learning is the auditory processing (Garcia, Pereira \& Fukuda, 2007). Research shows that most of children and adults with reading and learning complications suffer from problems in auditory attention and processing (Hämäläinen, Salminen \& Leppänen, 2012; Meng and et al, 2005). Auditory processing includes auditory discrimination, auditory memory, sequence, and order (Alpiner, McCarthy \& Patricia, 2000). Since poor readers have difficulty discriminating two auditory temporal stimuli (Steinbrink and et al, 2009; Hautus and et al, 2003), and they take more time to discriminate auditory stimuli(Heiervang, Stevenson \& Hugdahl, 2002.)and are more prone to make mistakes in such cases, it seems that one of the reasons for their failure in acquiring reading skills is their lack of auditory discrimination. According to these Ahissar \& et al showed that poor readers, have problems in auditory processing, as well- especially in cases that require discriminating frequencies(Ahissar and et al, 2000). There are a lot of studies that attribute reading problems to fundamental deficiencies in articulation and hearing systems (Partanen and et al, 2012). Consequently sound therapy is one of suggested treatments for such people. The effectivity of this method was firstly introduced by Tomatis, was confirmed in different studies and samples, but based the literature sound therapy is most influential in learning and reading disorders. For example Glimor and Gerritsen in their Metaanalysis- approved the effectivity of sound therapy on learning disorders including 
reading problems (Gilmor cited in Law and et al, 2017; Gerritsen, 2009). There are different clinical programs and procedures for sound therapy, and the classic one is employing music and creating vibration. Recent developments in technology are employed in designing the relevant tools. One of these new tools is the Forbrain headset which functions via vibrational stimulation to stimulate the bones and convey information through them into nervous system and brain. The dynamic filter utilized in the headset not only improves auditory quality, but also improves the performance of the vestibular system (Escera, 2014). This device is new and consequently there is little research on it. Escera's study showed that Forbrain headset improves focus and reduces reading problems in students. Since there is no unique and accepted method as a definite solution for reading problems, we cannot suffice to the existing treatments. New technologies should be tested, as well. Based on the above, the present study aims to answer the following question: is sound therapy able to help students with reading difficulties improve their reading skills?

\section{Materials and Methods}

This research was a quasi-experimental research with two groups (control and experimental) and pretest-posttest. The statistical population included all $3^{\text {rd }}$ grade students with reading difficulties in Tehran (2016-2017 academic years). The sample consisted of 20 students with reading difficulties selected based on research aim from available students who scored lower in Karami, Noori, and Moradi's reading test. Then, they were randomly assigned into two experimental and control groups (each group contained 10 participants). The inclusion criteria of participation in the study include: non-dyslexia based on dyslexia prognosis DSM-5, low raw scores in Karami, Noori, Moradi's reading test, refraining from medicine (Ritalin), age between 8 to 10 years old, and normal IQ scores based on Wechsler IQ test. The criteria for excluding the students from the study: Simultaneous disorders like ADHD, collapsed families (divorced or drug addicted parents, etc), sensory and motor problems were our criteria to exclude subjects. The following instruments were used to collect the data:

Standard Reading and Dyslexia Test: developed by Karami, Nouri, and Moradi (2008) includes several subscales for students from the $1^{\text {st }}$ to the $5^{\text {th }}$ grade. This test was used for 5 years from 2003 to 2007 on 1614 students in five different grades (770 males, and 884 females) in Tehran, Sanandaj, and Tabriz. After data collection, the data were statistically analyzed separately for each school grade in each city and the raw and normal scores were calculated. This test has been widely used in different studies 
(Behmard and et al, 2013). In the present study the Cronbach's alpha of .79 was obtained for the total test.

Wechsler IQ Test for Children Revised- Fourth Edition: In order to measure students' IQ, Wechsler IQ Test for children, 4th edition was used. This edition was standardized for a sample of 2200 American kids aging from 6 to 16 in 2002. The internal reliability coefficient of .94 for the test, .94 for each of four oral comprehension factors, .92 for cognitive reasoning, .92 for active memory, .88 for processing speed, and finally .97 for the test as a whole were estimated. Consequently, we can declare this instrument as reliable and stable. The present study makes use of the edition translated by Sadeghi, Abedi and Rabie (2011) and normalized in Isfahan. The results reported by them indicated a high degree of validity and reliability for the translated edition.

Before initiating the research, parents and students were thoroughly informed, and their written consent letters showed their willingness to participate in the study. All participants took a pretest. Then, 10 members of the intervention group took 20 sessions of sound therapy with Forbrain, while the control group received no intervention. Each session took 30 minutes (two periods each 15 minutes and 60 minutes break time in between) According to the standard protocol, using Forbrain for more than 15 minutes in children can lead to headache and dizziness.

During sound therapy, the students and the therapist were sitting face to face, and Forbrain headset was being used. The previous session exercises were reviewed as well until the student got enough master in that skill. The details of the sessions are reported in table 1. To complement the research and posttest, a week after the end of treatment sessions, both groups took Karami et al's Reading Standard Test. The obtained data were statistically analyzed using covariance and SPSS 22 software.

Table 1: The contents of sound therapy sessions

\begin{tabular}{|l|l|}
\hline Sessions & \multicolumn{1}{c|}{ Plan for Each Session } \\
\hline $\mathbf{1}^{\text {st }}$ & $\begin{array}{l}\text { Singing a song by the therapist and students imitation, reading a multi-sentence passage for the } \\
\text { student, and explaining its meaning in an informal language by the student, reading a book and } \\
\text { simultaneous reading by the student, and reading a book by a student on his own. }\end{array}$ \\
\hline $\mathbf{2}^{\text {nd }}$ & $\begin{array}{l}\text { Several words are said to the kid, and s/he repeats them in the same sequence. With her/his success, } \\
\text { the number of words will be increased. Some pictures are shown to the student and s/he says what is } \\
\text { shown loudly. Some words are pronounced and s/he repeats them. }\end{array}$ \\
\hline $\mathbf{3}^{\text {rd }}$ & $\begin{array}{l}\text { The student corrects therapist's mispronunciation. Words are pronounced imperfectly, and the } \\
\text { student is asked to pronounce perfectly. Some pictures are shown to the student and he is } \\
\text { encouraged to talk about them. }\end{array}$ \\
\hline $\mathbf{4}^{\text {th }}$ & $\begin{array}{l}\text { The alphabets are shown to the students and s/he is asked to pronounce them, and says a word that } \\
\text { begins with that letter. The letters are shown to the students and s/he pronounces them, then says a } \\
\text { word which ends in the intended letter. Some words are read and s/he repeats them, then s/he says } \\
\text { what its initial is. }\end{array}$ \\
\hline
\end{tabular}




\begin{tabular}{|c|c|}
\hline $5^{\text {th }}$ & $\begin{array}{l}\text { Some words are read and the kid says what it ends in. Marking syllables and sounds is done as } \\
\text { teachers usually pronounce. The kid and the therapist read a book together. }\end{array}$ \\
\hline $6^{\text {th }}$ & $\begin{array}{l}\text { The student reads the book by himself. Then s/he is required to correct the words mispronounced by } \\
\text { the therapist. Some pictures are shown to the kids, s/he makes a story based on the pictures. }\end{array}$ \\
\hline $7^{\text {th }}$ & $\begin{array}{l}\text { The therapist sings a song and the student sings simultaneously. A multi-sentence passage is read to } \\
\text { the students and s/he paraphrases it into informal language. The therapist and the kid read a book } \\
\text { together. Then, the kid reads by himself. }\end{array}$ \\
\hline $8^{\text {th }}$ & $\begin{array}{l}\text { Several words are said to the kid, and s/he repeats them in the same sequence. With each success the } \\
\text { number of words will be increased. Some pictures are shown to the student, and s/he says loudly } \\
\text { what they refer to. Some words are pronounced, and the student repeats them. }\end{array}$ \\
\hline $9^{\text {th }}$ & $\begin{array}{l}\text { The student is asked to correct the words mispronounced by the therapist. Words are pronounce } \\
\text { imperfectly, and s/he corrects them. Some pictures are shown to the student and s/he is required to } \\
\text { talk about them. }\end{array}$ \\
\hline $10^{\text {th }}$ & $\begin{array}{l}\text { The alphabets are shown to the kid, and s/he pronounces them. The kid says a word that begins with } \\
\text { the intended letter. The alphabets are shown again and the kid pronounces them. Then s/he is } \\
\text { required to say a word that ends in the intended letter. Some words are read and the kid repeats } \\
\text { them, and specifies their initial letters. }\end{array}$ \\
\hline $11^{\text {th }}$ & $\begin{array}{l}\text { Some words are read and the student repeats them, then specifies in what letter they end. The } \\
\text { syllables and sounds are emphasized as teachers articulate them. The therapist and the kid read a } \\
\text { book together. }\end{array}$ \\
\hline $12^{\text {th }}$ & $\begin{array}{l}\text { The student reads a book by himself. S/he is required to correct mispronounced words in the } \\
\text { therapist's speech. Some pictures are shown and the student makes a story based on them. }\end{array}$ \\
\hline $13^{\text {th }}$ & $\begin{array}{l}\text { The alphabets are shown to the student, s/he pronounces them and says a word beginning with the } \\
\text { intended letter. S/he does the same but says a word ending into the intended letter. Some words are } \\
\text { read to the kid and s/he repeats them, and specifies their initial letters. }\end{array}$ \\
\hline $14^{\text {th }}$ & $\begin{array}{l}\text { Some words are said and the kid repeats them in the same order. With each success, the number of } \\
\text { words will be increased. Some pictures are shown and the student says loudly what s/he sees in the } \\
\text { picture. Some words are pronounced and the student repeats them. }\end{array}$ \\
\hline $15^{\text {th }}$ & $\begin{array}{l}\text { The student is required to correct the words mispronounced by the therapist. Some words are } \\
\text { pronounced imperfectly, and the kid corrects them. Some pictures are shown, and the kid is required } \\
\text { to talk about them. }\end{array}$ \\
\hline $16^{\text {th }}$ & $\begin{array}{l}\text { The alphabets are shown to the student, s/he pronounces them and says a word beginning with the } \\
\text { intended letter. S/he does the same but says a word ending into the intended letter. Some words are } \\
\text { read to the kid and s/he repeats them, and specifies their initial letters. }\end{array}$ \\
\hline $17^{\text {th }}$ & $\begin{array}{l}\text { Some words are read and the student repeats them, then specifies in what letter they end. The } \\
\text { syllables and sounds are emphasized as teachers articulate them. The therapist and the kid read a } \\
\text { book together. }\end{array}$ \\
\hline $18^{\text {th }}$ & $\begin{array}{l}\text { The student reads a book by himself. S/he is required to correct mispronounced words in the } \\
\text { therapist's speech. Some pictures are shown and the student makes a story based on them. }\end{array}$ \\
\hline $19^{\text {th }}$ & $\begin{array}{l}\text { The therapist sings a song and the student sings simultaneously. A multi-sentence passage is read to } \\
\text { the students and s/he paraphrases it into informal language. The therapist and the kid read a book } \\
\text { together. Then, the kid reads by himself. }\end{array}$ \\
\hline $20^{\text {th }}$ & $\begin{array}{l}\text { The student is required to correct the words mispronounced by the therapist. Some words are } \\
\text { pronounced imperfectly, and the kid corrects them. Some pictures are shown, and the kid is required } \\
\text { to talk about them. }\end{array}$ \\
\hline
\end{tabular}

\section{Results}

The data are presented in two sections: descriptive and inferential. In descriptive section, the mean and standard deviation of participants' ages are presented in table 2.

Table 2: The mean and standard deviation of participants' ages

\begin{tabular}{|l|c|c|}
\hline Groups & Mean & Standard deviation \\
\hline Experimental & 7.95 & 0.926 \\
\hline Control & 7.90 & 0.518 \\
\hline
\end{tabular}


In inferential section, as pretest scores were considered as covariant variable, to determine its impact on the posttest, analysis of covariance was used. To this end, the assumptions of variance homogeneity and the normal distribution of scores- as main covariance assumptions- were investigated. The results of Levene test (table 3) approved the homogeneity of the data $(\mathrm{P}>0.05)$.

Result for Test of Homogeneity of Variances

\begin{tabular}{|l|l|l|l|l|}
\hline & $\begin{array}{l}\text { Levene } \\
\text { Statistic }\end{array}$ & df1 & df2 & Sig. \\
\hline Reading words & .044 & 1 & 28 & .836 \\
\hline Word chaining & .498 & 1 & 27 & .487 \\
\hline Rhyme & .628 & 1 & 28 & .435 \\
\hline Naming picture & 1.199 & 1 & 28 & .283 \\
\hline text comprehension & .515 & 1 & 28 & .479 \\
\hline Understanding words & .896 & 1 & 28 & .352 \\
\hline Deleting sounds & 1.978 & 1 & 28 & .171 \\
\hline Reading non-words & .009 & 1 & 26 & .926 \\
\hline
\end{tabular}

The data analysis based on Kolmogorov-Smirnov test shows the normal distribution of data in both groups. Since the prerequisites for covariance were observed, the data were analyzed using the covariance (The results are presented in table 4).

Table 4: Result of ANCOVA for posttest scores between experimental and control group

\begin{tabular}{|l|l|l|l|l|l|l|l|}
\hline \multicolumn{2}{|l|}{ Source of changes } & Type III SS & Df & Mean of squares & F & Sig. & Eta square \\
\hline $\begin{array}{l}\text { Total score } \\
\text { of Reading } \\
\text { Skills }\end{array}$ & $\begin{array}{r}\text { Pretest } \\
\text { groups }\end{array}$ & 246.64 & 1 & 246.64 & 0.206 & 0.655 & 0.012 \\
\hline
\end{tabular}

As evident in tables 4 , the $\mathrm{F}$ values are significant for all reading skills and $56 \%$ of the changes were caused by the intervention. Table 5 shows that these values are significant for all reading subscales expect for Rhyme and Reading non-words subscales.

Table 4: Result of MANCOVA for subscales of Reading Skills

\begin{tabular}{|l|l|l|l|l|l|l|}
\hline Source of changes & Type III SS & Df & Mean of squares & F & Sig. & Eta square \\
\hline Reading words & 2078.89 & 1 & 2078.89 & 13.77 & 0.002 & 0.48 \\
\hline Word chaining & 460.474 & 1 & 460.474 & 4.62 & 0.04 & 0.21 \\
\hline Rhyme & 17.62 & 1 & 17.62 & 3.78 & 0.07 & 0.17 \\
\hline Naming picture & 76.05 & 1 & 76.05 & 42.19 & 0.000 & 0.71 \\
\hline text comprehension & 117.55 & 1 & 117.55 & 20.97 & 0.000 & 0.55 \\
\hline Understanding words & \multicolumn{1}{|c|}{105.76} & 1 & 105.76 & 9.67 & 0.006 & 0.36 \\
\hline Deleting sounds & 473.68 & 1 & 473.68 & 13.39 & 0.002 & 0.44 \\
\hline Reading non-words & 0.285 & 1 & 0.285 & 0.002 & 0.96 & 0.00 \\
\hline letters cues & 305.48 & 1 & 305.48 & 16.84 & 0.001 & 0.49 \\
\hline category cues & 448.401 & 1 & 448.401 & 20.90 & 0.000 & 0.55 \\
\hline
\end{tabular}

Consequently, there is a significant difference in the mean scores of reading skills between control and experimental groups- the pretest affect is controlled. The 
comparison of adjusted means in both groups indicates that the mean for experimental group is higher than the mean of control group in both tests and most of reading skills subscales.

\section{Discussion}

The findings indicated that sound therapy, in the experimental group significantly, improved the reading skills compared to the control group. Although we didn't find identical studies in Iran or abroad, the results of similar studies support the present study. E.g. Mald's pioneering study indicated that auditory correction using Tomatis method (based on vibration) in male dyslexia students improved reading and spelling (Moretti and et al, 2002). Corbra also reported that employing the voice of people suffering from chronic and acute stutter to produce corrected signals improved their speech (Corbera and et al, 2005). Guerrero and Escera showed that Forbrain headset helps to reduce students' reading difficulties (Corbera and et al, 2005; Guerrero, 2015). Layeghian showed that games improving auditory skills can boost the capacity of auditory-explanative memory, sharpen auditory discrimination, and improve dictation of students with learning disorders (Layeghian Javan, Jahanshiri \& Montazeriyan, 2016).

Since the paths of visual and audial are totally connected in brain, and both are engaged in reading, training and adjusting listening is a way to improve reading performance. Poor listening skills are main obstacles to grow lingual skills. When spoken sounds are not perfectly conveyed to the children, they will face problems in converting sounds into lingual symbols. The right ear is the leader influentially transferring speech sounds to brain, because the right ear is directly connected with the left hemisphere- the main language processing center. Based on the reports on children suffering from reading problems, especially dyslexia, fail to achieve the right ear dominance; consequently what they hear is disordered, segmented, and uninfluential. The sometimes used the right ear, and sometimes the left one as dominant, and as a result sounds reach to the brain in different speeds, and scattered (Juadry \& Juadry, 2009).

The balance between the two brain hemispheres is fundamentally important to overcome reading problems. This balance does not exist in people with reading problems, and the paths leading to thorough voice analysis are disrupted. Consequently, sound therapy is one the successful treatments for them. On the one hand, vibration stimulates and trains the ears, and ear is taught to receive and interpret information in a different way. On the other hand, the right ear is trained to be dominant, and this reduces reading problems to a large extant. So far, many studies have confirmed the effectivity 
of Tomatis sound therapy method (Gerritsen, 2009). They showed that this therapy can reduced reading problems or totally obviate them. The classic sound therapy model for children suffering from reading difficulties include 10 to 20 hours of auditory training with music (using vibration to stimulate hearing cortex) followed by reading aloud practice (to train the right ear dominance).

In sound therapy with Forbrain, both types of practice take place simultaneously and with a better quality. In this method, on the one hand, vibrations are made to stimulate the nervous system and bones to convey information through bones into brain and nervous system. The set has got a filter to improve auditory quality and the performance of vesibular system. The diffusion of sound via through bones has a significant role in emergence of phonological cycle which in turn is responsible for diffusion of stored speech information. This process leads to improvement of speech and fluency. The methods based on auditory stimulation provide the chance to increase muscular capacity of the ear (Escera, 2015). Studies on cats revealed that passive and long term exposure to augmenting sounds helps to reorganize the hearing map on the cortex (Pienkowski \& Eggermont, 2012; Norena and et al, 2006). Scarin used audio stimulation and claimed that this method resulted in improving auditory reception and speeding up the reception of auditory signals (AbediKoupaei and et al, 2013). On the other hand, the special layout of the headset makes the right ear dominant, and this in turn facilitates the reception and processing of auditory signals. Thus, we expect plastic changes in audio-oral cycles which lead to more organized and influential transfer of auditory information to the cortex.

As a whole, it seems that, sound therapy with Forbrain improves riding skills in students. Correction of sound analysis paths leads to improvement in reading skills. The results obtained from this study revealed that sound therapy can be an influential and effective intervention to treat students with reading difficulties. Because of effectivity of the present intervention in treatment of auditory discrimination, the same method can be employed to treat or prevent other learning disorders. Although sound therapy is not a perfect treatment for all types of learning disorders, it is a major component since hearing plays a prominent role in learning process without its training and adjustment learning will be really hard. Some of restrictions faced in this study were limitation of research to the 3rd elementary school grades, the lack of follow up studies because of time limitation, as well as novelty of intervention method. These factors make generalization of the findings difficult. Sampling based on the availability and ignoring age and gender are other limitations of the study. Consequently, we recommend the 
researchers to conduct similar studies in other regions of the country and on different educational grades so that generalization- based on the age and gender characteristicsbecomes plausible.

\section{References}

AbediKoupaei M, Poushaneh K, Zade Mohammadi A, Siampour N. (2013). Sound Therapy: an Experimental Study with Autistic Children. Procedia - Social and Behavioral Sciences. 84: 626-630.

Ahissar M, Protopapas A, Reid M, Merzenich MM. (2000). Auditory processing parallels reading abilities in adults. Proceedings of the National Academy of Sciences. 97: 6832-6837.

Allah Radi M, Modaresi L, Mohammadi E. (2001). Study and comparison of visual perceptions, auditory and visual and sequencing memory and phonological awareness skills in children with dyslexia and normal children[dissertation]. Tehran Iran: univ of Welfare and Rehabilitation Sciences.

Alpiner J, McCarthy G, Patricia A. (2000). Rehabilitative audiology:children and adults.Third Edition. Maryland (USA), Lipicott Williams \& wills; 120-128.

Behmard F, Estaki M, Ashayeri H, Asadpour H. (2013). The effectiveness of gross and fine motor training on reducing symptoms of dyslexia. Journal of learning disabilities. 2(2): 25-32

Corbera S, Corral MJ, Escera C, Idiazábal MA. (2005)Abnormal speech sound representation in developmental stuttering. Neurology. 65:1246-1252.

Escera Carles. Neural mechanisms underlying Forbrain ${ }^{\circledR}$ effects. (2014); available from:

https://www.forbrain.com/uploads/editor/files/University_of_Barcelona_Neural_m echanisms underlying Frobrain effects.pdf

Garcia VL, Pereira LD, Fukuda Y. (2007). Selective attention: psi performance in children with learning disabilities. Brazilian Journal of Otorhinolaryngology. 73(3):404-11

Gerritsen J. A review of research done on Tomatis auditory stimulation. (2009). Avalable from:

http://www.sacarin.com/code/Review\%20of\%20Tomatis\%20Research.pdf 
Guerrero BA. (2015). Forbrain ${ }^{\circledR}$ 's effect on the reading process[dissertation]. Madrid Spine:UNIR (Universidad Internacional de La Rioja - Universidad en Internet.

Hämäläinen J.A, Salminen H.K, Leppänen P.H. (2012). Basic Auditory Processing Deficits in Dyslexia Systematic Review of the Behavioral and Event-Related Potential/ Field Evidence. Journal of Learning Disabilities. 46(5): 1-8.

Hautus MJ, Setchell GJ, Waldie KE, Kirk IJ. (2003). Age-related improvements in auditory temporal resolution in reading impaired children. Dyslexia. 9: 37-45.

Heiervang E, Stevenson J, Hugdahl K. (2002). Auditory processing in children with dyslexia. Journal of Child Psychology \& Psychiatry \& Allied Disciplines. 43: 931938.

Juadry P, Juadry R. (2009). Sound Therapy Music to Recharge your brain. Australia: 15230.

Law J, Dennis J.A, Charlton JV. (2017). Speech and language therapy interventions for children with primary speech and/or language disorders. Cochrane Database of Systematic Reviews. Available from: http://cochranelibrarywiley.com/doi/10.1002/14651858.CD012490/full.

Layeghian Javan MJ, Jahanshiri M, Montazeriyan F. (2016). Effect of listening skills games on strengthening auditory memory, auditory sensitivity and Children's learning disability dictate treatment. 6th International Congress on Child and Adolescent Psychiatry, Tabriz, Iran.

Meng X, Sai X, Wang C, Wang J, Sha Sh, Zhou X. (2005). Auditory and speech processing and reading development in Chinese school children: behavioural and ERP evidence. Dyslexia. 11(4): 292-310.

Moretti R, Bava A, Torre P, Antonello RM, Cazzato G. (2002). Reading errors in patients with cerebellar vertnis lesions. Journal of Neurology. 249(4): 461-468.

Norena AJ, Gourevitch B, Aizawa N, Eggermont JJ. (2006). Spectrally enhanced acoustic environment disrupts frequency representation in cat auditory cortex. Nature Neuroscience. 9(7): 932-9.

Palomo-Álvarez C, Puell MC. (2009). Relationship between oculomotor scanning determined by the DEM test and a contextual reading test in schoolchildren with 
reading difficulties. Graefe's Archive for Clinical and Experimental Ophthalmology. 247: 1243-1249.

Partanen M, Fitzpatrick K, Mädler B, Edgell D, Bjornson B, Giaschi DE. (2012). Cortical basis for dichotic pitch perception in developmental dyslexia. Brain Lang. 123(2):104-12.

Pienkowski M, Eggermont, JJ. (2012). Reversible long-term changes in auditory processing in mature auditory cortex in the absence of hearing loss induced by passive, moderate-level sound exposure. 2012; 33(3): 305-314.

Sadeghi A, Rabiee M, Abedi MR. (2011). Validation and Reliability of the Whechsler Intelligence scale for children- IV. Developmental Psychology: Iranian Psychologist. 7(28): 377-386.

Sen HS. (2009). The relationsip between the use of metacognitive strategies and reading comprehension. Procedia Social and Behavioral Sciences. 1(15): 2301-2305.

Steinbrink C, Ackermann H, Lachmann T, Riecker A.(2009). Contribution of the anterior insula to temporal auditory processing deficits in developmental dyslexia. Hum Brain Mapp.30(8):2401-11. 